1-5.

Cardiac Surgery Jinnah Hospital, Lahore.

Correspondence Address:

Dr. Tayyab Pasha

Cardiac Surgery Jinnah Hospital, Lahore.

tayyab_pasha@hotmail.com

Article received on:

03/02/2016

Accepted for publication:

28/03/2016

Received after proof reading:

04/05/2016

\section{EARLY OUTCOMES; OFF-PUMP MULTIPLE OR TOTAL ARTERIAL CORONARY REVASCULARIZATION.}

Dr. Tayyab Pasha1, Dr. Rafaqat Ahmed², Dr. Muhammad Amir ${ }^{3}$, Dr. Amir Iqbal ${ }^{4}$, Dr. Ayesha Siddiqa (RPH) ${ }^{5}$

ABSTRACT... Objectives: Off pump TACR/MACR performed in experienced hands has comparable results to on pump TACR/MACR. Period: January-2012 to December-2015. Material and method: 405 patients with two and three vessel coronary artery disease (two \& three VCAD) underwent OPCAB at the department of cardiac surgery, Jinnah hospital, Lahore. 73 of them got total or multiple arterial coronary revascularizations. 34 patients (41\%) had two VCAD and 47 (59\%) had three VCAD. Total arterial revascularization was performed in 70 (95.8\%) patients using right internal mammary artery and left internal mammary artery and/or radial artery. $3(4.10 \%)$ patients got multiple arterial grafts using BITA, RA and SVG. Results: There was no death reported in first 30 days post operatively. Deep sternal wound infection occurred in only one patient. The rate of perioperative stroke and renal failure was zero. Two (2.46\%) patients had acute $\mathrm{Ml}$ and 1 patient was reopened due to bleeding. Conclusion: We conclude that early outcome of OPCAB total or multiple arterial coronary revascularizations, in experienced hands, are as safe and effective as ONCAB.

Key words: $\quad$ Total arterial revascularization, multiple arterial revascularizations, bilateral internal mammary artery, ONCAB, OPCAB, two or three vessel coronary artery disease

Article Citation: Pasha T, Ahmed R, Amir M, Iqbal A, Siddiqa A. Early outcomes; off-pump multiple or total arterial coronary revascularization. Professional Med $\mathrm{J}$ 2016;23(5):583-588. DOI: 10.17957/TPMJ/16.3269

\section{INTRODUCTION}

Coronary artery bypass graft surgery has been the procedure of choice worldwide for coronary artery disease. This surgery uses left internal mammary artery (LIMA) as a conduit to left anterior descending artery (LAD) and saphenous vein to other occluded or stenosed arteries. It is observed that results of off pump TACR/MACR performed in experienced hands are comparable to on pump TACR/MACR. The drawbacks of cardiopulmonary bypass are expressed as physiological disturbance secondary to the exposure of blood to oxygenators, filters and plastic tubes which destroy red blood cells. Moreover, it has been the reason that activates the inflammatory system and releases the cytokines that precipitates the enhanced capillary leakage. This presents potential threat to most of the other organs of human body. ${ }^{1}$

Off pump coronary artery surgery for TACR is equally useful without compromising perfection of revascularization. Avoidance of CBP offers many other benefits that include remarkable decreased use of mechanical ventilator and duration of ICUstay. Moreover, the manipulation of the anterior aorta during clamping and cannulation is a prime independent risk factor for stroke. The embolism caused by atherosclerotic material and/or air can be the possible cause. ${ }^{2}$

OPCAB technique demonstrates decreased mortality and morbidity in terms of Stroke. The merits of this technique depend on the patient's general condition at the time of the surgery, the ejection fraction of the heart, and coronary anatomy, as well as on the surgeon's experience. ${ }^{3,4}$

In a restricted experience, 95\% unselected, consecutive OPCAB patients recovered without any major wound complication. It has been well documented that off-pump CABG using LITA grafting can be adopted routinely with excellent early outcomes without any harm. ${ }^{5}$ 
The left coronary artery system can be bypassed with BITAs. But it is not always possible to bypass the left and right coronary artery (RCA) with pedicled IMAs. Bypassing the RCA with a radial artery is an alternative option in that case. The aim of this study was to evaluate the early outcomes among patients who have undergone off-pump total/multiple arterial revascularization using BITA and RA in double or triple-vessel disease.

\section{MATERIAL AND METHODS}

From January-2012 to December-2015, 405 patients with double \& triple-vessel disease underwent OPCAB at the cardiac surgery department, Jinnah hospital, Lahore. CAD patients with valvular disease were excluded. Patients with emergency or redo CABG, and those with single vessel disease were also excluded from this study. Patients with isolated CABG and patients with previous $\mathrm{PCl}$ were included. Moreover, all smoker, hypertensive and diabetic patients were also included. Among these 405 patients, 73 patients were selected for OPCAB, 34 (41.9\%) patients were having with 2VCAD and $47(59.02 \%)$ with 3VCAD. Total arterial revascularization was performed in $70(95.8 \%)$ patients using radial artery or right internal mammary artery with left internal mammary artery. $3(4.2 \%)$ patients got multiple arterial grafts using LIMA, RIMA, RA and SVG. (15\%) of the above 73 patients got LIMA /RIMA configuration and (32.5\%) got LIMA/ RADIAL configuration (Figure-1). Out of the above 47 three vessel disease patients, (31.4\%) got LIMA/Radial Sequential configuration, (14.2\%) got LIMA/RIMA/Radial configuration, $(4.2 \%)$ got LIMA Sequential/Radial artery configuration,(1.42\%) got LIMA sequential/Radial Sequential configuration,(4.2\%) got BIMA/RA/ SVG configuration (Figure-2).

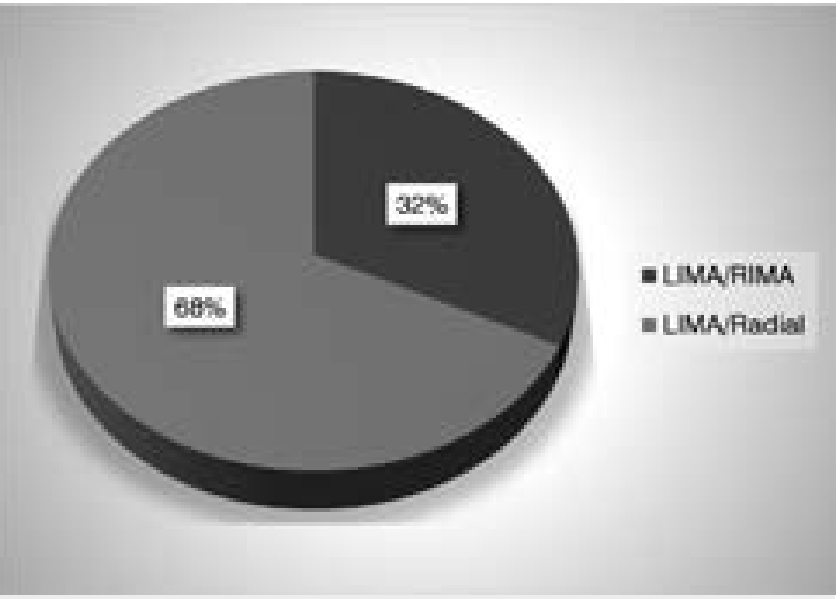

Figure-1. Patients who got double arterial coronary revascularizations

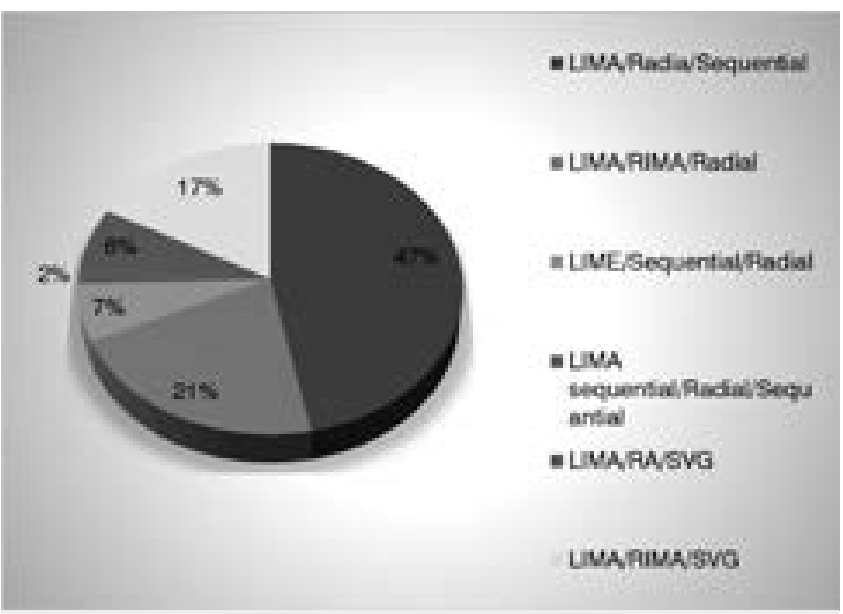

Figure-2. Patients who got multiple arterial coronary revascularizations

We used arterial grafts among patients having morethan $90 \%$ stenosis in RCA. We retrospectively analysed the clinical data of patients preserved in records after approval of Ethical Review Committee of Jinnah Hospital. The patient's graft distribution is given in table-l below.

\begin{tabular}{|c|c|c|c|c|c|c|c|c|}
\hline Year & $\begin{array}{c}\text { LIMA/ } \\
\text { RIMA }\end{array}$ & $\begin{array}{c}\text { LIMA/ } \\
\text { RDIAL }\end{array}$ & $\begin{array}{c}\text { LIMA/RA } \\
\text { SEQ }\end{array}$ & $\begin{array}{c}\text { BIMA/ } \\
\text { RADIAL }\end{array}$ & $\begin{array}{c}\text { LIMA SEQ/ } \\
\text { RA }\end{array}$ & $\begin{array}{c}\text { LIMA\& RA SEQ } \\
\text { Both }\end{array}$ & $\begin{array}{c}\text { BIMA/ } \\
\text { RA SVG }\end{array}$ & Total \\
\hline 2012 & & 02 & - & - & - & - & - & 02 \\
\hline 2013 & 01 & 09 & 11 & 04 & 01 & 01 & 01 & 28 \\
\hline 2014 & 02 & 07 & 11 & 01 & 02 & - & 02 & 25 \\
\hline 2015 & 08 & 05 & - & 05 & - & - & - & 18 \\
\hline Total & 11 & 23 & 22 & 10 & 03 & 01 & 03 & 73 \\
\hline
\end{tabular}




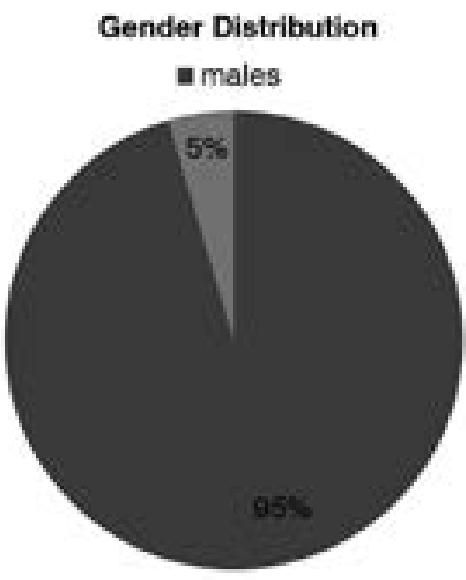

Figure-3. Chart showing patients gender distribution

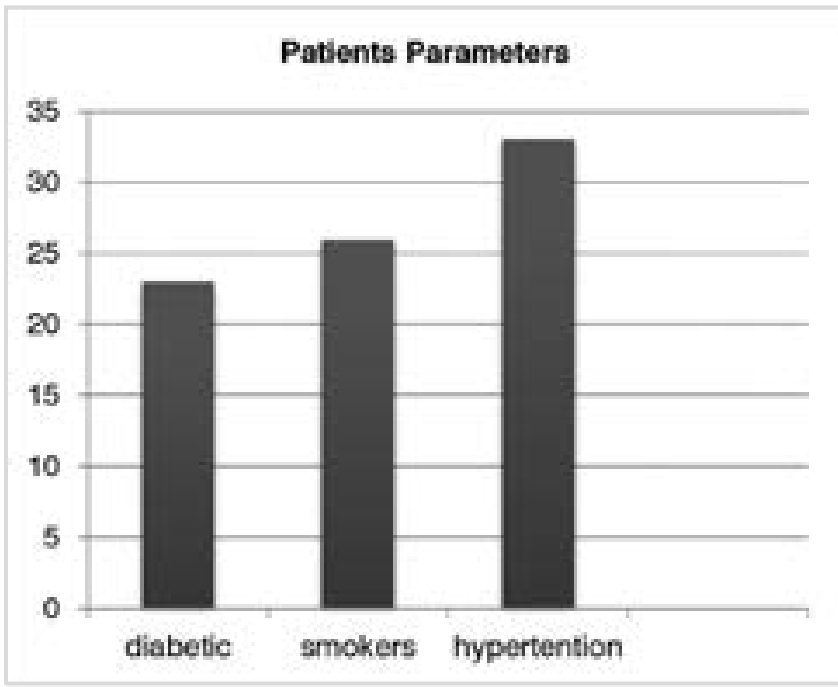

Figure-4. Patient parameters leading to cardiac event

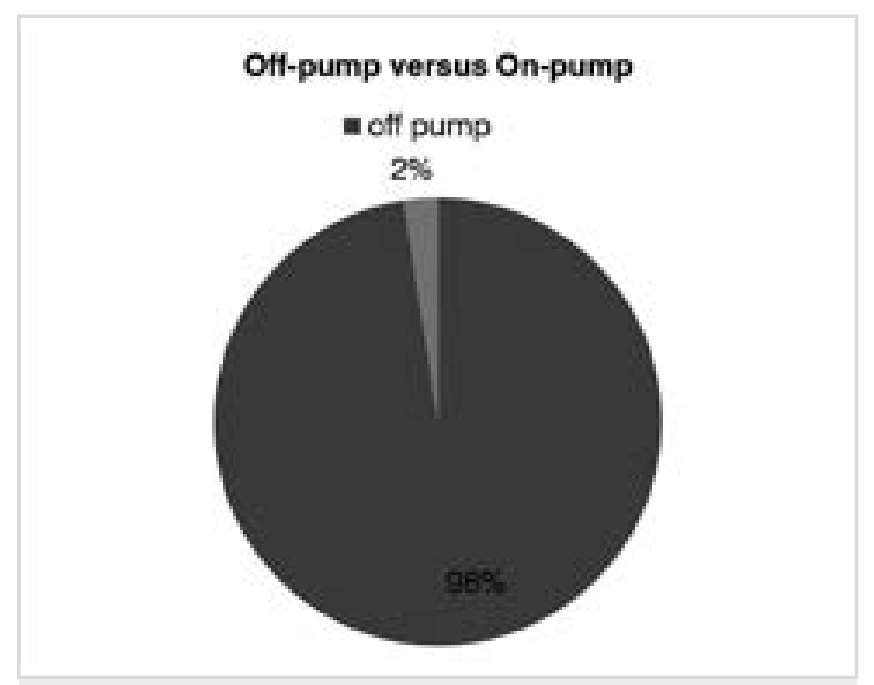

Figure-4. Patient parameters leading to cardiac event
Postoperative myocardial infarction is defined as new $Q$ waves observed in electrocardiogram or a peak creatine kinase-MB greater than $5 \%$ of the creatine kinase. A postoperative stroke is defined as a central neurologic deficit that persists for more than 72 hours, and is confirmed by computed tomography (CT) or magnetic resonance imaging (MRI). Cardiac event may be defined as a myocardial infarction, heart failure, reoccurrence of angina and sudden death. Short hospital stay that is up to 6 days at our tertiary care center and long hospital stay is above 6 days. Long hospital stay was reported in 21 (28.7\%) patients and short hospital stay was reported in $52(71.2 \%)$ patients.

\section{Hospital stay of patients}

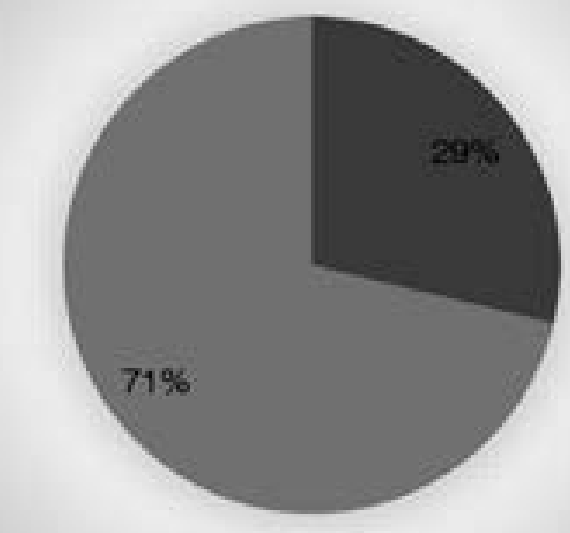

- long hospital stay = short hospital stay

\section{SURGICAL TECHNIQUE}

We prepared IMAs by the pedicle technique using sharp dissection and clipping of the branches. We performed Allen's test first then radial artery was harvested from non-dominant forearm. It was preserved in papaverine solution. Heparin was administered at a dose of $150 \mathrm{lU} / \mathrm{kg}$ to achieve the target activated clotting time of 300 s or more. A deep pericardial stay suture was used, by lifting the heart under gauze piece and the pericardium by tip of suture needle, taking utmost care of posterior mediastinal structures. After arteriotomy to obtain a bloodless field, the target coronary 
artery was shunted by using different sized intra luminal shunts.

LIMA was anastomosed on circumflex territory while RIMA on LAD or PDA with a continuous running 7-0 Prolene suture (Ethicon). Similarly RA was anastomosed to circumflex territory or PDA in the same manner. All anastomoses on LAD and diagonal territory of heart were performed by stabilizing the part of heart with the use of Medtronic Octopus. The anastomoses on circumflex or PDA territory by using both star fish and Medtronic octopus. After completion of top ends on aorta, heparin was partially reversed with protamine sulfate $(0.5 \mathrm{mg} / \mathrm{kg})$. Minimum use of diathermy was ensured for haemostasis. Bone wax was used to stop bleeding from sternum. The pericardium and thoracic cavities were washed with gentamycin solution. 08 or more wires were used to close the sternum. Vancomycin powder was applied on the sternum and subcutaneous tissues. Subcutaneous tissues were approximated by vicryl $2 / 0$ in two layers. After cleaning the wound edges with pyodine, skin was approximated with continuous running subcuticular 3/0 vicryl suture. Mepore antiseptic dressing was applied later on.

\section{STATISTICAL ANALYSIS}

The number of mean distal anastomoses per patient was 2.45. The patient parameters after surgery are given in table 2 below.

\begin{tabular}{|l|c|}
\hline No of distal anastomosis & 2.52 \\
\hline ICU stay & 03 DAYS \\
\hline Hospital stay & $07-08$ DAYS \\
\hline REOPERATION FOR BLEEING & $1(1.23 \%)$ \\
\hline CVA & 00 \\
\hline DSWI & 01 \\
\hline THIRTY DAY MORTALITY & 00 \\
\hline \multicolumn{2}{|c|}{ Table-II. Patient parameters after surgery } \\
\hline
\end{tabular}

\section{EARLY OUTCOME}

No patient was reported to die within first 30 days. Deep sternal wound infection occurred in one patient $(1.23 \%)$. The rate of perioperative stroke and renal failure was zero. Two patients $(2.46 \%)$ had acute $\mathrm{Ml}$ and one patient was reopened for bleeding. The mean intensive care unit and postoperative hospital stays were 3 days and 7-8 days, respectively.

\begin{tabular}{|l|c|}
\hline Number of patients followed up & $72(88.8 \%)$ \\
\hline Angina & 0 \\
\hline Reopening for bleeding & $1(1.23 \%)$ \\
\hline Acute myocardial infarction & $2(2.46 \%)$ \\
\hline Cardiac death & 0 \\
\hline Sudden death & 0 \\
\hline Table-III. Table indicating early outcome of patients
\end{tabular}

\section{DISCUSSION}

The forthcoming evidence supporting the patency of the BIMA and the RA as conduits has become attractive topic for discussion of total arterial revascularization. ${ }^{10,11,12,13}$ This methodology is linked to enhance long-term survival. This is due to the greater patency of arterial conduits and the protective effects of arteries on the native circulation. ${ }^{14}$ Spasm of heel side of graft is most commonly occurring problem peri-operatively, but can also occur days to months later. Some other factors that can lead to arterial graft failure are also reported. Partial occlusion usually occurs soon after surgery and the likelihood may be some technical mishap. Localized stenosis is due to local trauma, or a local vascular wall abnormality which is not recognized at the time of harvest. Thirdly and most importantly, competitive flow is the cause for arterial graft occlusion. Such free grafts do not "reopen" when the native coronary becomes occluded, although there are reports of in situ LITA grafts doing so. Arterial grafts are superior in patency as they never become atheromatous. ${ }^{14,15,16,17}$ Long-term survival after $\mathrm{CABG}$ is considered to be in proportional correlation with late patency of the selected conduits and grafts constructed. ${ }^{18}$ Thus, the superiority in long-term survival observed among TACR or MACR patients, compared with LIMA/ SV patients, may be related to the accelerated atherosclerosis of vein grafts with their higher rates of subsequent occlusion around 10 years [19]. Arterial grafts possess various mechanisms that potentiate blood flow and resistance to atherosclerosis. ${ }^{20}$ 
Since bilateral internal thoracic artery (BITA) grafting to the left anterior descending coronary artery and circumflex coronary arteries offer the best long-term survival and the lowest rates of re-intervention in patients undergoing CABG. Following these reasons we adopted this approach. However, the best graft for the right coronary artery in patients with triple-vessel disease has not been well established. The right coronary artery can be bypassed with a saphenous vein graft, the radial artery, RGEA or a combination of LITA and RITA grafts.

\section{CONCLUSION}

We concluded that total arterial revascularization or multiple arterial coronary revascularizations using OPCAB with BIMA and RA grafts is safe and effective, in patients with double or triple-vessel disease provided good surgical technique is being used. It has comparable results to ONCAB surgery technique.

\section{LIMITATIONS}

In this study we used a retrospective and nonrandom design. We did not routinely perform preoperative and postoperative myocardial perfusion tests; therefore, we could not determine competitive flow patterns that contribute to myocardial ischemia. Furthermore, the followup was not up to that extend to draw a definite conclusion.

\section{Copyright@ 28 March, 2016.}

\section{REFERENCES}

1. John R, Choudhri AF, Weinberg AD, Ting W, Rose EA, Smith $\mathrm{CR}$ et al. Multicenter review of preoperative risk factors for stroke after coronary artery bypass grafting. Ann Thorac Surg. 2000; 69(1):30-6.

2. Delawer Reber; Marcus Fritz; Alfred Germing; Peter Marks; Axel Laczkovics. Early outcome after offpump coronary artery bypass grafting: effect on mortality and stroke Early Outcome of a Randomized Comparison of Off-Pump and On-Pump Multiple Arterial Coronary Revascularization.

3. Junjiro Kobayashi, MD; Tadashi Tashiro, MD; Masami Ochi, MD; Hitoshi Yaku, MD; Go Watanabe, MD; Toshihiko Satoh, MD; Osamu Tagusari, MD; Hiroyuki Nakajima, MD; Soichiro Kitamura, MD; for the Japanese Off-Pump Coronary Revascularization Investigation (JOCRI) Study Group.
4. Dorsa A, Rossi A. Extubación postoperatoria inmediata (ultra fast-track) en cirugía sin CEC. In: XXXI Congreso Argentino de Cardiología; 2004.

5. Lisboa LAF, Dallan LAO, Puig LB, Abreu Filho C, Leca $R C$, Dallan LAP et al. Seguimento clínico a médio prazo com uso exclusivo de enxertos arteriais na revascularização completa do miocárdio em pacientes com doença coronária triarterial. Rev Bras Cir Cardiovasc. 2004; 19(1):9-16.

6. Off-pump Bilateral Internal Thoracic Artery Grafting.

7. Kamales Kumar Saha,Mandar M. Deval,Ajay Kumar, Ram P. Kaushal, M,Kakalee K. Saha, Rinu V. Jacob,Ratnaprobha Adsul, Lukash Jagdale, Cohen R. Off-pump coronary bypass grafting. In: Franco KL, Verrier ED. Advanced therapy in cardiac surgery. 2nd ed. B.C. Decaer; 2003. P.89-101.

8. Buxton, B.F., Shi, W.Y., Tatoulis, J., Fuller, J.A., Rosalion, A., and Hayward, P.A. Total arterial revascularization with internal thoracic and radial artery grafts in triple-vessel coronary artery disease is associated with improved survival. J Thorac Cardiovasc Surg. 2014; 148: 1238-1243.

9. Locker, C., Schaff, H.V., Dearani, J.A., Joyce, L.D., Park, S.J., Burkhart, H.M. et al. Multiple arterial grafts improve late survival of patients undergoing coronary artery bypass graft surgery: analysis of 8622 patients with multivessel disease. Circulation. 2012; 126: 1023-1030.

10. Zacharias, A., Schwann, T.A., Riordan, C.J., Durham, S.J., Shah, A.S., and Habib, R.H. Late results of conventional versus all-arterial revascularization based on internal thoracic and radial artery grafting. Ann Thorac Surg. 2009; 87: 19-26.

11. Deb, S., Cohen, E.A., Singh, S.K., Une, D., Laupacis, A., Fremes, S.E. et al. Radial artery and saphenous vein patency more than 5 years after coronary artery bypass surgery: results from RAPS (Radial Artery Patency Study). J Am Coll Cardiol. 2012; 60: 28-35.

12. Hayward, P.A., Gordon, I.R., Hare, D.L., Matalanis, G., Horrigan, M.L., Rosalion, A. et al. Comparable patencies of the radial artery and right internal thoracic artery or saphenous vein beyond 5 years: results from the Radial Artery Patency and Clinical Outcomes trial. J Thorac Cardiovasc Surg. 2010; 139: 60-65.

13. Tatoulis J, Buxton BF, Fuller JA. The right internal thoracic artery: is it underutilized? Curr Opin Cardiol 2011; 26:528-35.

14. Tatoulis J, Buxton BF, Fuller JA, et al. Patencies of $\mathbf{2 1 2 7}$ 
Arterial to Coronary Conduits over fifteen years. Ann Thorac Surg 2004; 77:93-101.

15. Tatoulis J, Buxton BF, Fuller JA. The right internal thoracic artery: the forgotten conduit--5,766 patients and 991 angiograms. Ann Thorac Surg 2011; 92:9-15; discussion 15-7.

16. Lytle BW, Blackstone EH, Sabik JF, et al. The effect of bilateral internal thoracic artery grafting on survival during 20 postoperative years. Ann Thorac Surg 2004; 78:2005-12; discussion 2012-4.

17. Dimitrova KR, Hoffman DM, Geller CM, et al. Arterial grafts protect the native coronary vessels from atherosclerotic disease progression. Ann Thorac Surg 2012; 94:475-81.
18. Cameron A, Davis KB, Green G, et al. Coronary bypass surgery with internal-thoracic-artery grafts: effects on survival over a 15-year period. N Engl J Med 1996; 334:216-9.

19. Lytle BW, Loop FD, Cosgrove DM, et al. Long-term (5 to 12 years) serial studies of internal mammary artery and saphenous vein coronary bypass grafts. $J$ Thorac Cardiovasc Surg 1985; 89:248-58.

20. He GW, Liu ZG. Comparison of nitric oxide release and endothelium derived hyperpolarizing factormediated hyperpolarization between human radial and internal mammary arteries. Circulation 2001;104:I344-9.

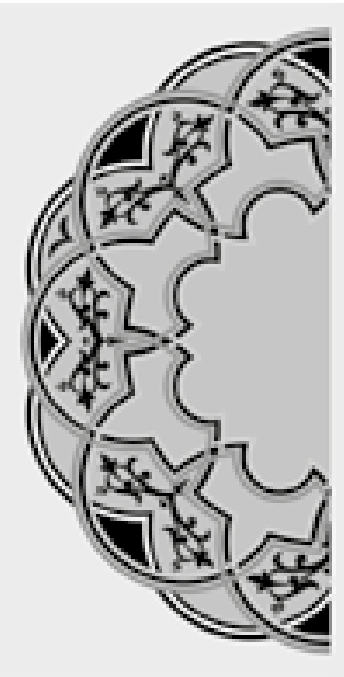

\section{"Your child follow your example not your advice."}

Unknown

\section{AUTHORSHIP AND CONTRIBUTION DECLARATION}

\begin{tabular}{|c|c|c|c|}
\hline Sr. \# & Author-s Full Name & Contribution to the paper & Author $=\mathbf{s}$ Signature \\
\hline 1 & Dr. Tayyab Pasha & Corresponding Author & \\
\hline 2 & Dr. Rafaqat Ahmed & Co-Author & \\
\hline 3 & Dr. Muhammad Amir & Co-Author & \\
\hline 4 & Dr. Amir lqbal & Co-Author & $\therefore M C R$ \\
\hline 5 & Dr. Ayesha Siddiqa (RPH) & Co-Author & \\
\hline
\end{tabular}

